\title{
ESTUDO DE TORRE DE VENTO: ENSAIOS EM TÚNEL DE VENTO EM EDIFICAÇÕES RESIDENCIAIS
}

\author{
WINDCATCHER STUDY: WIND TUNNEL TESTS IN RESIDENTIAL
} BUILDINGS

\section{ESTUDIO DE TORRE DE VIENTO: ENSAYO DE TÚNEL DE VIENTO EN EDIFÍCIOS RESIDENCIALES}

\author{
SILVA, Anne Caroline Oliveira ${ }^{1}$ \\ CHRISTAKOU, Evangelos Dimitrios ${ }^{2}$ \\ SILVA, Lenildo Santos da ${ }^{3}$ \\ SILVA JÚNIOR, Félix Alves da ${ }^{4}$ \\ GURJAO, Claudia Marcia Coutinho ${ }^{5}$ \\ ${ }^{1}$ Departamento de Engenharia Civil e Ambiental, Faculdade de Tecnologia, Universidade de Brasília. Brasília - DF, \\ Brasil. anneoliv6@gmail.com \\ ORCID: 0000-0002-6306-8059 \\ 2 Departamento de Engenharia Civil e Ambiental, Faculdade de Tecnologia, Universidade de Brasília. Brasília - DF, \\ Brasil.vvangelis54@gmail.com \\ ORCID: 0000-0002-4454-1234 \\ ${ }^{3}$ Departamento de Engenharia Civil e Ambiental, Faculdade de Tecnologia, Universidade de Brasília. Brasília - DF, \\ Brasil. Lenildo_s@hotmail.com \\ ORCID: 0000-0001-5099-6123 \\ ${ }^{4}$ Departamento de Engenharia Civil e Ambiental, Faculdade de Tecnologia, Universidade de Brasília. Brasília - DF, \\ Brasil. felixalsilva@gmail.com \\ ORCID: 0000-0003-3871-903X \\ ${ }^{5}$ Departamento de Engenharia Civil e Ambiental, Faculdade de Tecnologia, Universidade de Brasília. Brasília - DF, \\ Brasil.cgurjao@unb.br \\ ORCID: 0000-0001-5025-3952
}




\title{
Resumo
}

A adoção da ventilação natural em substituição à ventilação mecânica pode contribuir para a redução do consumo de energia elétrica das residências. Dentre as soluções possíveis está a utilização de torres de vento, solução arquitetônica original milenar do povo persa, para o condicionamento de ambientes internos, reduzindo o consumo de energia com ganhos significativos no quesito do conforto térmico. As torres de vento aplicadas às edificações podem funcionar como consequência da diferença de pressão do vento que incide na fachada ou devido à variação de temperatura: o ar frio entra por uma abertura, refrigerando o interior do local e empurrando 0 ar quente para fora do edifício. $O$ desenvolvimento do trabalho foi dividido nas seguintes etapas metodológicas: 1) determinação dos modelos reduzidos, 2) definição dos parâmetros de ensaio, 3) programação de sensores e 4) ensaio em túnel de vento. Os resultados obtidos no túnel de vento permitiram avaliar a melhor configuração de torre de vento para cada caso, visando reduzir a temperatura interna dos ambientes. Além disso, foi possível concluir que a variação de temperatura de $0,5^{\circ} \mathrm{C}$ alcançada pode contribuir para a redução de consumo de energia elétrica e ao mesmo tempo preservar ou ampliar o conforto térmico dos usuários.

Palavras-Chave: eficiência energética; torre de vento; conforto térmico; túnel de vento; ventilação natural.

\begin{abstract}
The adoption of natural ventilation to replace mechanical ventilation can contribute to reducing the residential consumption of electrical energy. Among the possible solutions is the use of windcatchers, an ancient architectural solution from the Persian people, for the conditioning of indoor environments, reducing the energy consumption and reaching efficient levels of thermal comfort. Windcatchers applied to the buildings can function through the differences of wind pressure that affect the facade or due to temperature variation: cold air enters through an opening, cooling the interior of the room and pushing hot air out of the building. The development of the work followed the methodological steps: 1) determination of the reduced models, 2) definition of the test parameters, 3) sensor programming and 4) wind tunnel test. The results obtained in the wind tunnel made it possible to evaluate the best windcatcher configuration for each case, aiming to reduce the internal temperature of the environments. In addition, it was possible to conclude that the temperature variation of $0.5^{\circ} \mathrm{C}$ achieved can contribute to the reduction of electricity consumption and, at the same, time preserve or increase the thermal comfort of users.
\end{abstract}

Key-Words: energy efficiency; wind catcher thermal comfort; wind tunnel; natural ventilation

\begin{abstract}
Resumen
La adopción de la ventilación natural como sustituta de la ventilación mecánica puede contribuir a reducir el consumo de electricidad del hogar. Entre las posibles soluciones está el uso de torres de viento - la solución arquitectónica original del antiguo pueblo persa - para el acondicionamiento de ambientes internos, reduciendo el consumo de energía con ganancias significativas en bienestar termal. Las torres de viento aplicadas a los edificios pueden funcionar como consecuencia de la diferencia de la presión del viento en la fachada o debido a la variación de la temperatura: el aire frío entra por una abertura, enfriando el interior del lugar y empujando el aire caliente fuera del edificio. El desarrollo de los trabajos se dividió en las siguientes etapas metodológicas: 1) determinación de los modelos reducidos, 2) definición de los parámetros de prueba, 3) programación de los sensores y 4) pruebas en un túnel de viento. Los resultados obtenidos en el túnel de viento permitieron evaluar la mejor configuración de torre de viento para cada caso, con el objetivo de reducir la temperatura interna de los ambientes. Además, fue posible concluir que la variación de temperatura de $0,5^{\circ} \mathrm{C}$ lograda puede contribuir a la reducción de consumo de energía y al mismo tiempo preservar o ampliar el bienestar térmico de los usuarios.
\end{abstract}

Palabras-clave: Eficiencia Energetica; Torre de Viento; Bienestar Termal; Túnel de Viento; Ventilación Natural 


\section{Introdução}

A preocupação em projetar residências que proporcionem conforto térmico ao usuário e que, ao mesmo tempo, diminuam o impacto no meio ambiente, vem crescendo cada vez mais, principalmente devido ao atual cenário de emergência climática em que vivemos. Considerando que o aquecimento global é um dos maiores e mais importantes desafios da sociedade hoje em dia.

O consumo anual de energia elétrica no Brasil é de 555 TWh (Terawatt-hora), com crescimento médio, nos últimos dez anos, de 4\% ao ano (QUEIROZ, 2014). Pesquisas recentes realizadas pela Empresa de Pesquisa Energética (EPE) indicam que o Brasil está entre os dez maiores consumidores de energia elétrica do mundo, sendo as regiões sul e centro oeste as líderes de crescimento de consumo. Tais dados indicam o alto nível de demanda e a necessidade cada vez maior de novos estudos e investimentos para mitigar os efeitos negativos destas demandas.

Buscar meios passivos para condicionar edificações é uma das formas potenciais para mitigar o impacto do consumo de energia elétrica na construção civil, obter melhor qualidade do ar livre de fungos e conforto térmico no interior da edificação. Porém, ao longo de todo o território brasileiro é possível identificar uma grande variedade climática. Em virtude disso, encontrar soluções construtivas que sejam únicas e, ao mesmo tempo, atendam de forma eficiente a questão de conforto térmico é ainda mais difícil.

No Brasil, alguns dos exemplos de edificações que utilizam estratégias de ventilação natural para o conforto térmico de seus usuários são os hospitais da Rede Sarah Kubitschek, desenvolvidos pelo arquiteto João Filgueiras Lima, mais conhecido como Lelé. Nos hospitais da rede Sarah em vários pontos do país, Lelé elaborou estratégias diferentes para cada capital, como, por exemplo, as galerias de tubulações subterrâneas para conduzir ar fresco para o interior, direcionando o ar quente por saídas através de telhado do tipo shed (NUNES, 2014).

Além das soluções propostas por Lelé, destaca-se também o uso milenar de torres de vento para obtenção de ventilação natural. As torres de vento foram muito utilizadas na arquitetura persa e árabe e ainda hoje são alternativas muito utilizadas, mesmo que reinterpretadas, por promoverem renovação do ar e manterem bons níveis de conforto térmico. Visando à análise de alternativas sustentáveis para a substituição de sistemas mecânicos de condicionamento de ar, o presente trabalho buscou avaliar o funcionamento e a eficácia de torres de vento, a partir de ensaios em túnel de vento utilizando sensores de Arduino.

O objetivo geral deste trabalho foi avaliar o desempenho térmico e a eficiência da utilização de torres de vento em uma residência localizada no Setor Habitacional Jardins Mangueiral, no Distrito Federal, comparando o benefício desta solução com a utilização de aparelhos de condicionamento de ar. Como objetivos específicos:

- Destacar a importância da utilização de alternativas de ventilação natural para obter conforto térmico e consequentemente reduzir o consumo de energia elétrica das edificações;

- Demonstrar o funcionamento do sistema de torres de vento, desde sua concepção até sua utilização atualmente;

- Identificar as metodologias necessárias para a realização de ensaios em túnel de vento com modelos reduzidos reproduzidos em MDF;

- Programar sensores de Arduino para a determinação dos parâmetros de conforto térmico de uma edificação.

\section{Objetos de estudo}

O emprego de controles térmicos naturais é uma maneira de alcançar índices satisfatórios de conforto térmico ao passo que se racionaliza o uso de energia, tornando seu consumo mais sustentável uma vez que eles proporcionam ao ambiente a redução dos efeitos causados por climas quentes 
promovendo a redução do excesso de calor resultante no interior das edificações (FROTA E SCHIFFER, 2016). Tais controles térmicos podem ser obtidos adequando a arquitetura da edificação, posicionando ambientes ou utilizando soluções de ventilação natural a partir de estudos do fluxo de vento, da geometria solar e dos dados climáticos da região.

\subsection{Torres de vento}

A utilização de torres de vento (Figura 1) é uma alternativa para a obtenção de eficiência e conforto térmico em edificações por meio de ventilação natural as quais podem funcionar tanto como captadoras quanto extratoras de ar, promovendo a renovação do ar e conforto higrotérmico do ambiente.

Figura 1: Torre de vento. Vista em corte de uma residência com torre de vento.

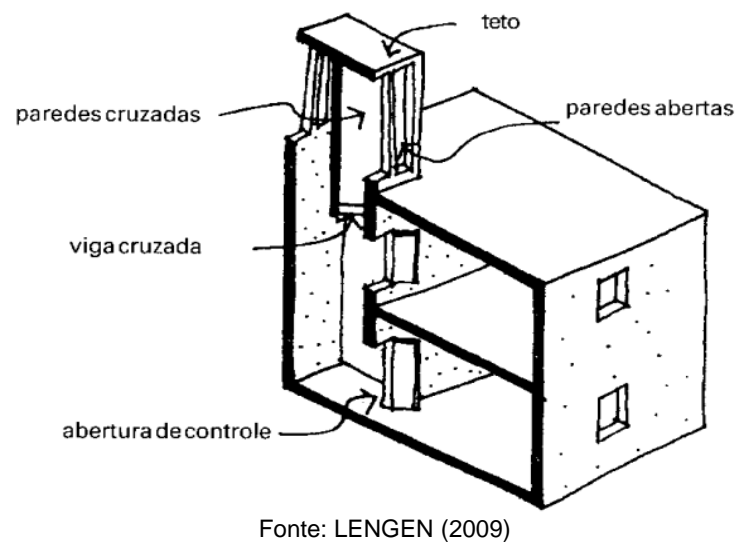

No passado, com a forte influência do império persa, as torres de vento passaram a ser difundidas e encontradas na arquitetura do Oriente Médio, Paquistão e Índia. Não é fácil determinar a primeira origem da torre de vento no mundo. No entanto, a primeira evidência histórica foi encontrada no local de Tappeh Chackmaq, perto da cidade de Shahrood, no Irã, que remonta a 4000 aC. (JOMEHZADEH ET AL., 2016)

Atualmente, as torres de vento voltaram a merecer as atenções de arquitetos ocidentais, utilizando dos tradicionais conceitos arquitetônicos persas/árabes para empregar em seus modernos edifícios, como no Centro de Visitantes do Parque Nacional de Zion nos Estados Unidos (Figura 2).

Figura 2: Parque Nacional de Zion, Sringdale, EUA.

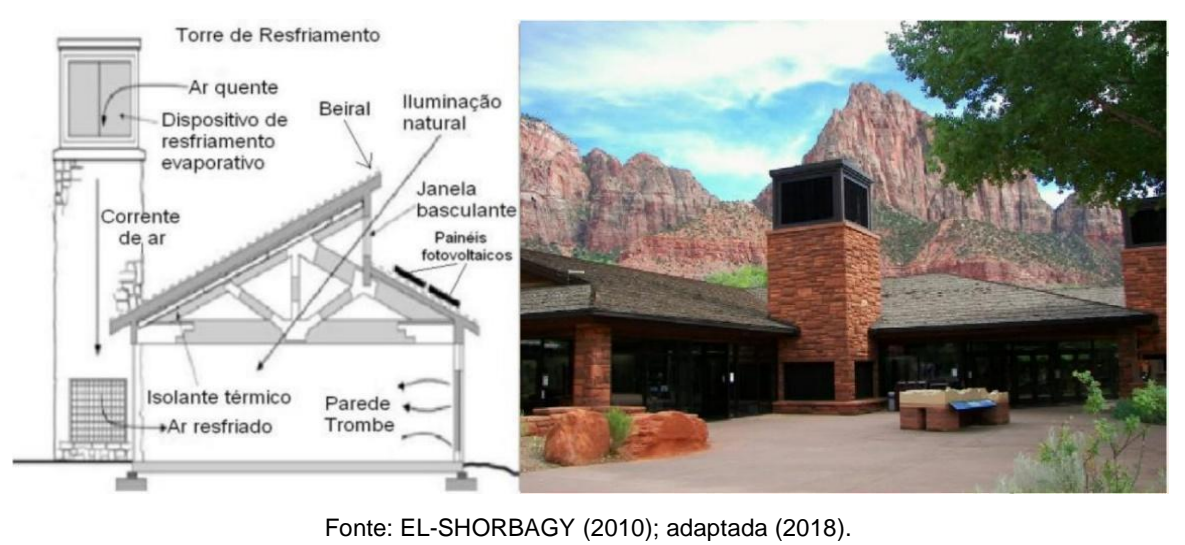

As torres de vento são captadores e extratores de vento que permitem a entrada de ar frio para o interior de edificações e liberam o ar quente para seu exterior. De acordo com A'zami (2005), existem dois mecanismos principais de funcionamento dessas estruturas: a ventilação por meio de diferença de 
temperatura e ventilação por meio da diferença de pressão existente nas aberturas.

A ventilação por meio da diferença de pressão (Figura 3) ocorre devido à associação das pressões positivas e negativas que ocorrem na edificação. De acordo com o posicionamento da torre, uma face terá incidência solar, enquanto sua face oposta necessariamente estará à sombra. Na face em que houver sombreamento o ar captado será mais fresco e, sendo mais pesado, é direcionado para o interior do ambiente pressionando o ar quente, e mais leve, para a abertura que está voltada para o sol.

Figura 3: Ventilação por diferença de pressão.
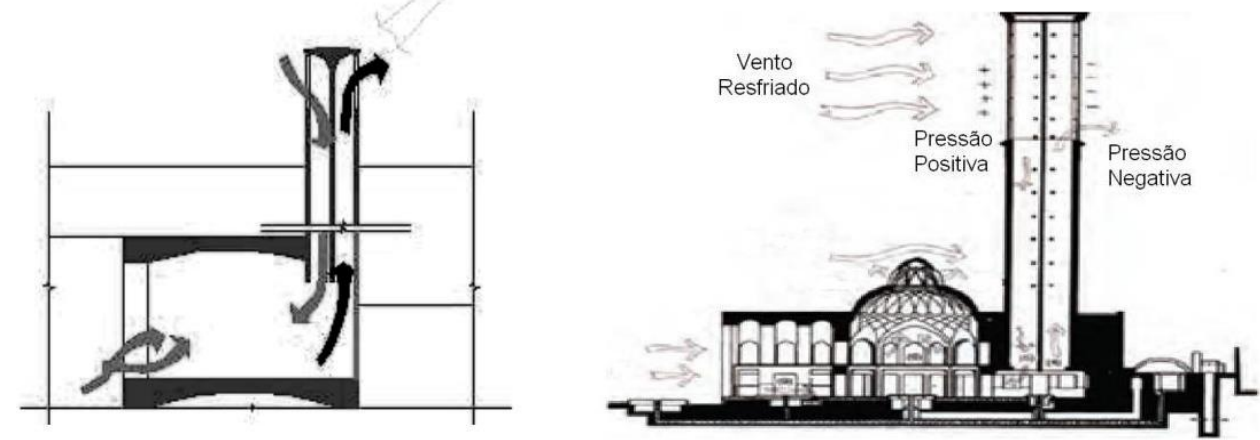

Fonte: ANDRADE (2013); A'ZAMI (2005).

Quando não há incidência muito forte de corrente de vento, as torres de vento podem funcionar por meio da diferença de temperatura. Analisando a Figura 4, durante o dia, ao ocorrer incidência solar na face direita da edificação, o ar proveniente das janelas aquece e sobe, no lado oposto, sem a incidência solar, o ar que entra pela abertura da torre de vento estará mais fresco, formando vácuo na região da torre, levando o ar frio que entra na abertura esquerda da torre de vento para baixo.

Figura 4: Ventilação por diferença de temperatura.

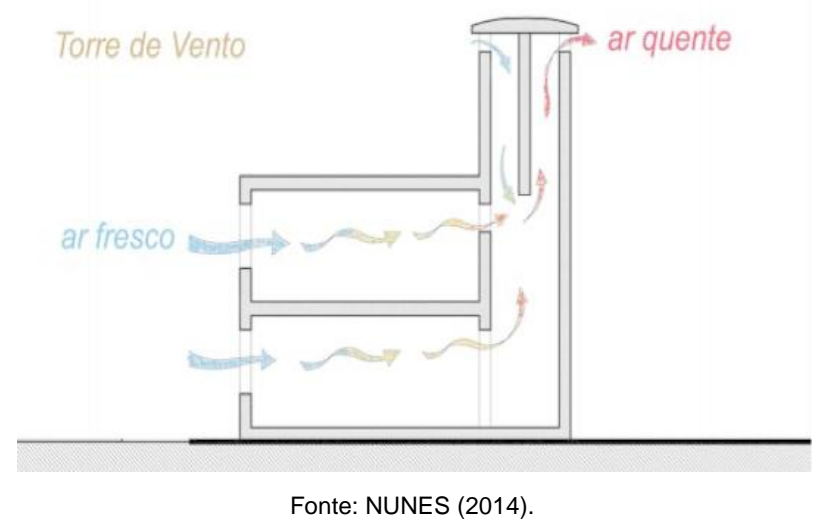

De toda forma, é preciso projetar a torre de vento de acordo com a variação predominante de direção do vento na região. Se existir uma direção constante de vento no local, as aberturas da torre poderão ser dispostas perpendicularmente à direção dos ventos, mas, se o vento variar entre direções opostas será necessário adaptar a torre com aberturas opostas também. (TORRES, 2018).

Apesar da eficiência que as torres de vento proporcionam quanto às questões de conforto térmico e eficiência energética das edificações, também apresentam algumas limitações e desvantagens. Dentre 
as desvantagens podemos citar a baixa eficiência de ventilação quando executadas em locais com ventos de baixa velocidade, a entrada de poeira e insetos pelas aberturas da torre e a dissipação de ar em caso de torres com mais de uma abertura. No entanto, existem maneiras de minimizar tais desvantagens utilizando diretrizes adequadas de projeto das torres. (BAHADORI, 1985).

\subsection{Arduino}

O Arduino é um sistema computacional capaz de programar para processar entradas e saídas entre o dispositivo e os componentes externos conectados a ele utilizando micro controladores. (MCROBERTS, 2011).

O projeto Arduino foi criado em 2005 pelo professor Massimo Banzi no Interaction Design Instituite, com o objetivo de utilizar tecnologia em projetos de design com linguagem mais simples, utilização fácil e de baixo custo. Desde então, o Arduino foi sendo desenvolvido e hoje sua versão mais recente, o Arduino UNO (Figura 5), se tornou padrão para projetos, devido ser uma placa mais versátil capaz de realizar projetos de diferentes áreas.

Figura 5: Arduino UNO.

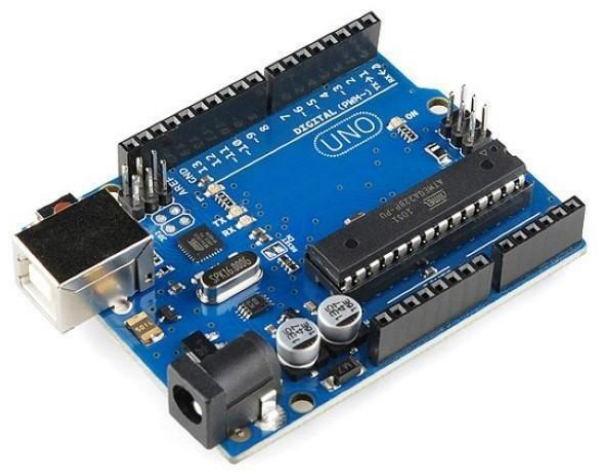

Fonte: THOMSEN (2015).

Por ser uma plataforma de prototipagem de código aberto, o Arduino é capaz de interagir com outros sistemas a partir da aquisição de variáveis físicas através de sensores. Seus códigos, projetos e esquemas podem ser utilizados livremente por qualquer pessoa, o que torna o sistema de baixo custo.

Os sensores conectados ao Arduino são dispositivos eletroeletrônicos que transformam em variações elétricas as variações de diferentes grandezas físicas como pressão, temperatura, umidade, velocidade do vento, distâncias, dentre outras (CASTRO, 2016).

\subsection{Região de Estudo}

Os estudos de ventilação natural realizados neste trabalho foram desenvolvidos para uma edificação do Setor Habitacional Jardins Mangueiral (Figura 6), localizado na Região Administrativa de São Sebastião, no Distrito Federal, situado no centro-oeste do Brasil, 1.160 metros acima do nível do mar.

De acordo com a Secretaria de Economia do Distrito Federal (SEDF), o Setor Jardins Mangueiral é proveniente da primeira Parceria Público-Privada (PPP) habitacional do país, com estimativa de ocupação de 30 mil moradores nas oito mil unidades habitacionais construídas desde 2009.

O Jardins Mangueiral faz parte do Programa Minha Casa, Minha Vida, do Governo Federal, voltado para pessoas com renda entre quatro e doze salários mínimos. Segunda a SEDF, as habitações são compostas por casas de dois e três quartos, além de apartamentos de dois quartos, distribuídas por 15 quadras, ocupando uma área de 200 hectares. 
Figura 6: Região de Estudo.

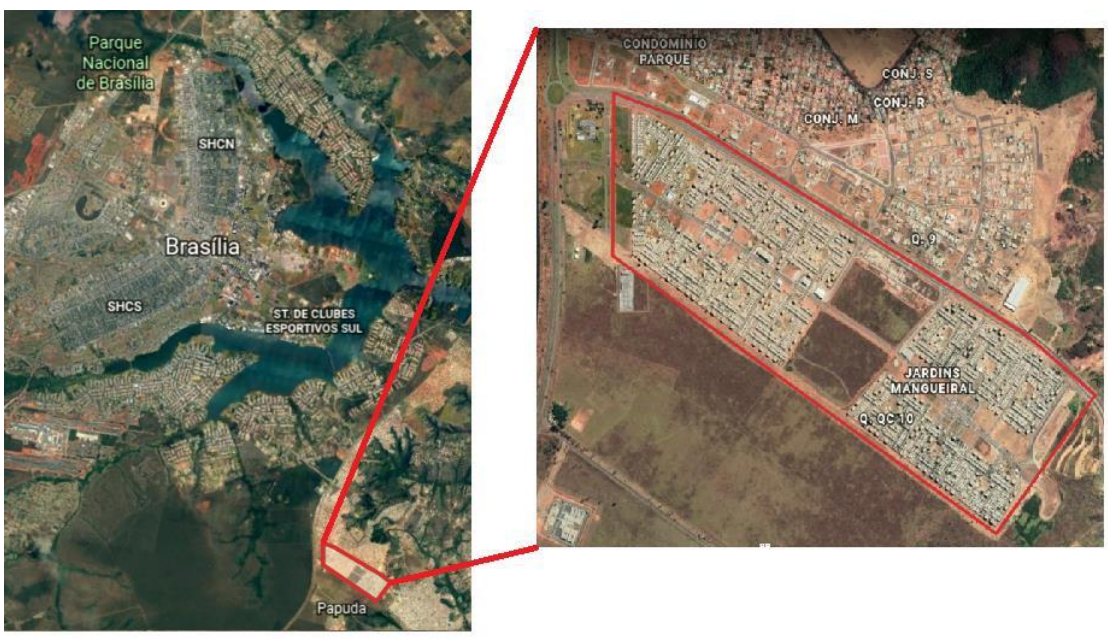

Fonte: Google Maps (2018).

A escolha dessa região ocorreu devido ao padrão arquitetônico das edificações construídas, em que todas as residências possuem divisões internas semelhantes. Além disso, por fazer parte de um Programa do Governo Federal, os resultados do estudo podem ser aplicados não somente para a região especificada, mas também para futuras áreas de implantação do Programa, com seus respectivos ajustes a depender da escala de conforto térmico desejado e considerando as especificidades de cada microclima, alcançando, assim, um significativo apelo social.

A região de estudo apresenta um clima tropical de altitude marcado por duas estações bem definidas: a seca, com baixos níveis de umidade relativa do ar e altas temperaturas; e a chuvosa, que mesmo elevando a umidade do ar, permanece com temperaturas altas.

Ao longo do ano, as temperaturas máximas e mínimas em Brasília se aproximam do limite de conforto térmico (Figura 7). De acordo com a plataforma Projeteee (Projetando Edificações Energeticamente Eficientes), desenvolvida pelo PROCEL/Eletrobrás e a Universidade Federal de Santa Catarina, a aplicabilidade da utilização de ventilação natural na região de estudo é em média de $22 \%$, sendo mais eficiente nos períodos da tarde e da noite e na primavera e no verão.

Figura 7: Temperaturas médias de Brasília em 2016.

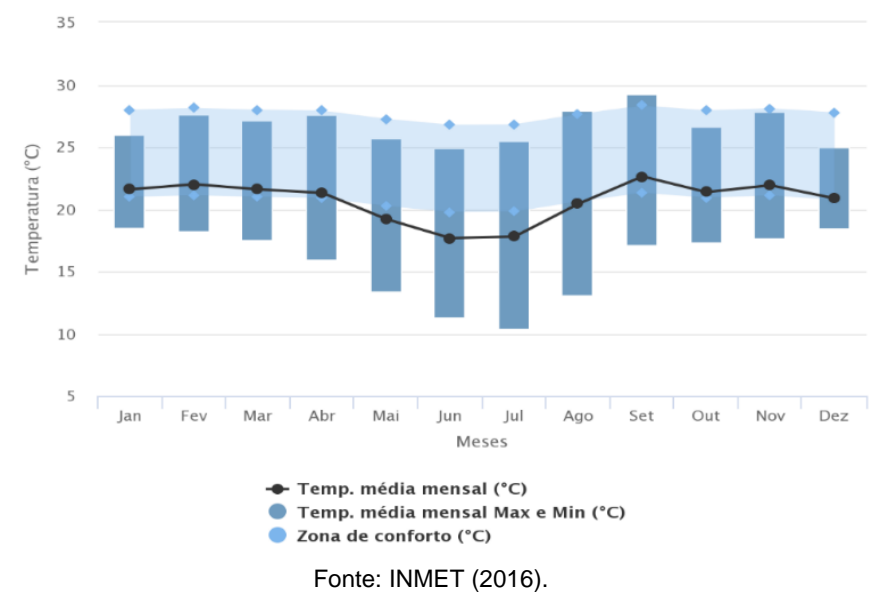

Já a velocidade média do vento em Brasília (Figura 8) varia significativamente ao longo do ano. Entre os meses de junho e outubro os ventos são mais fortes, com velocidade média acima de $11,4 \mathrm{Km} / \mathrm{h}$, 
enquanto nos demais meses a velocidade média fica em torno de $8,9 \mathrm{Km} / \mathrm{h}$. (CONDIÇÕES..., 2018).

Figura 8: Velocidade média do vento em Brasília.

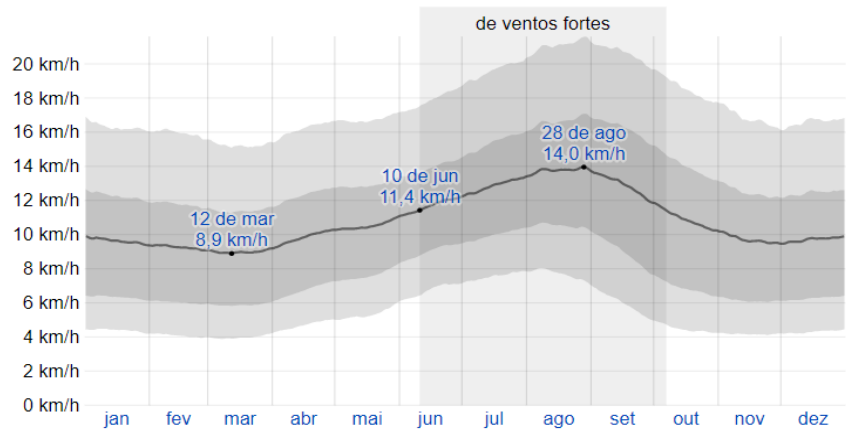

Fonte: WEATHER SPARK (2018).

Para Givoni (1994), a ventilação natural pode garantir conforto quando a temperatura máxima externa é menor que $30^{\circ} \mathrm{C}$. Assim, para os períodos de temperatura mais elevada em Brasília, o funcionamento das torres de vento pode ser satisfatório e a velocidade do ar no interior da edificação indicará a aplicabilidade da ventilação diurna ou noturna.

\subsection{Edificação de Estudo}

A simulação do uso de torre de vento foi realizada com base nos projetos arquitetônicos de uma casa de dois pavimentos, em que o pavimento térreo (Figura 9) é composto por sala de estar, lavabo e cozinha, enquanto o pavimento superior (Figura 10) possui dois quartos e banheiro social.

Figura 9: Pavimento térreo da casa em estudo.

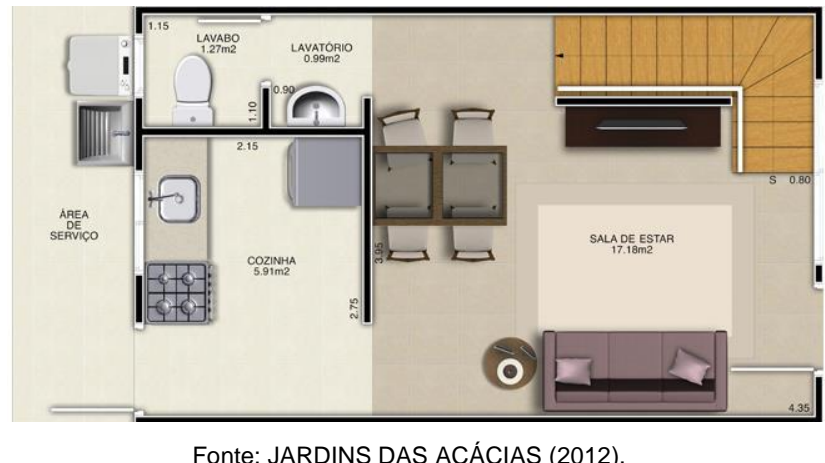

Figura 10: Pavimento superior da casa em estudo.

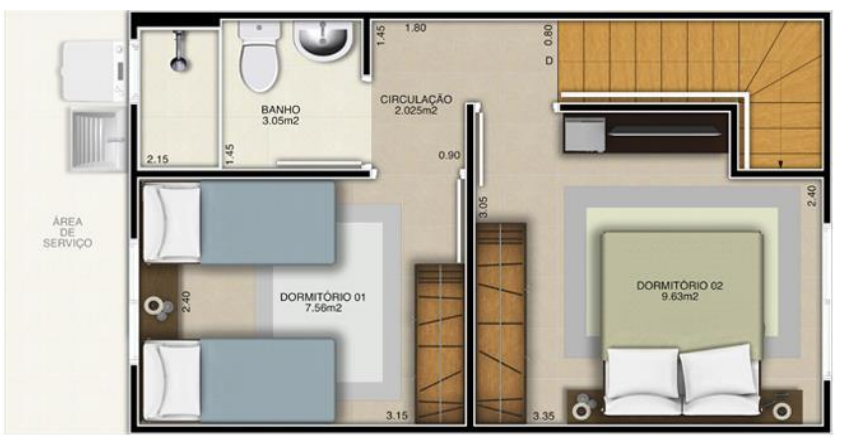

Fonte: JARDINS DAS ACÁCIAS (2012)

A residência estudada para implementar a torre de vento possui aproximadamente $60 \mathrm{~m} 2$ de área 
construída. Durante os períodos mais quentes do ano, a temperatura interna fica ainda mais elevada e a percepção de ventilação nos ambientes não é alta mesmo com as aberturas frontais e traseiras. De acordo com os usuários, para suprir a baixa ventilação interna e conforto térmico é necessária a utilização de ventiladores e aparelhos de ar condicionado, elevando o consumo e, consequentemente, o gasto de energia elétrica.

Assim, como exemplo de residências com consumo de energia elétrica por meio de condicionadores mecânicos de ambientes justificou-se a escolha dessa edificação como modelo para implantação do sistema de torre de vento, demonstrando sua viabilidade, economia e eficiência energética.

\section{Metodologia}

Para a realização do estudo proposto e alcançar os objetivos da pesquisa, foram adotadas as seguintes etapas metodológicas: 1) determinação e modelagem dos modelos reduzidos, 2) definição dos parâmetros de ensaio, 3) montagem da bancada de sensores e 4) ensaio em túnel de vento. $O$ fluxograma do processo metodológico é apresentado a seguir na figura 11.

Figura 11: Fluxograma da metodologia implementada.

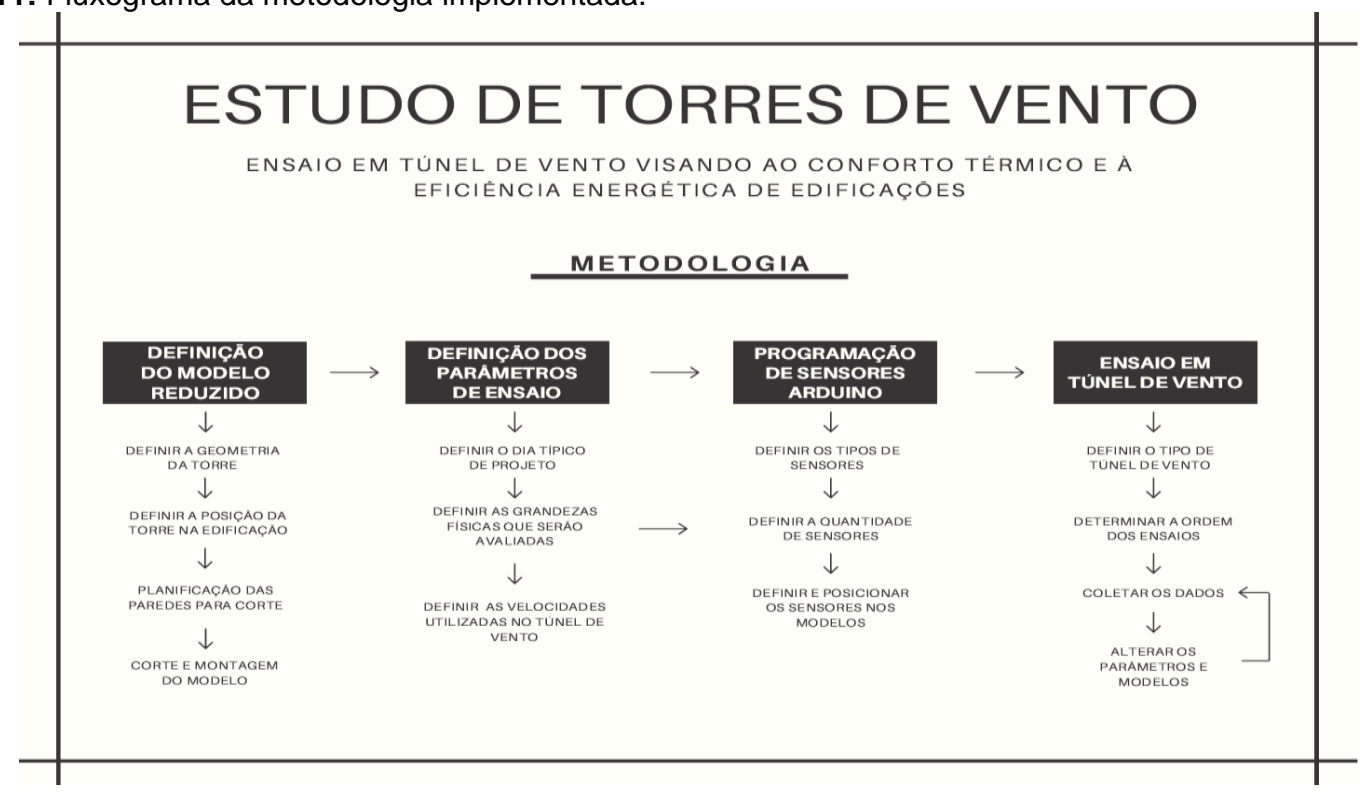

Fonte: autores (2019)

A elaboração do modelo reduzido teve como base as plantas arquitetônicas anteriormente apresentadas nas Figuras 09 e 10. A fim de complementar o estudo e avaliar as condições de conforto para uma residência de um pavimento, foi construído outro modelo de uma edificação térrea composta por sala de estar integrada à cozinha, um banheiro social e um dormitório (Figura 12).

Figura 12: Planta adaptada para casa térrea de 1 quarto.

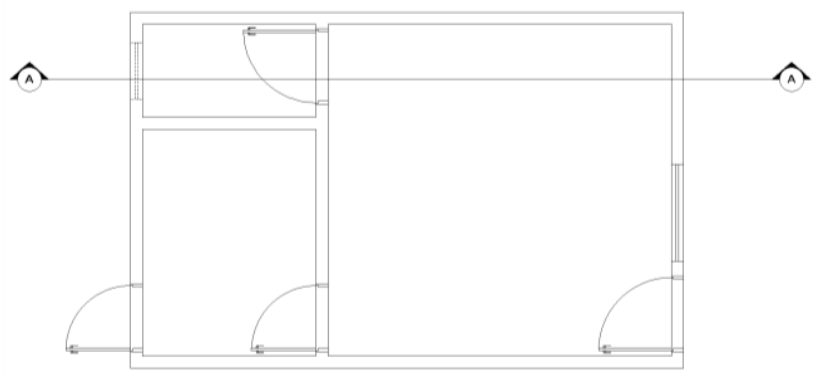

Fonte: autores (2019) 
Para a confecção do modelo reduzido foi definida a geometria da torre estudada e seu posicionamento na cobertura da edificação. Em seguida, o modelo foi montado por meio dos cortes feitos a laser em chapa MDF, unidos por cola especial para esse material.

\subsubsection{Definição da geometria da torre de vento}

Foram adotados três modelos de torres de vento com aberturas bidirecionais (Figura 13). A definição de utilização desses três modelos ocorreu devido a edificação estudada apresentar dimensões reduzidas e ser o tipo de geometria comumente utilizada.

Figura 13: Torres bidirecionais projetada para o estudo.

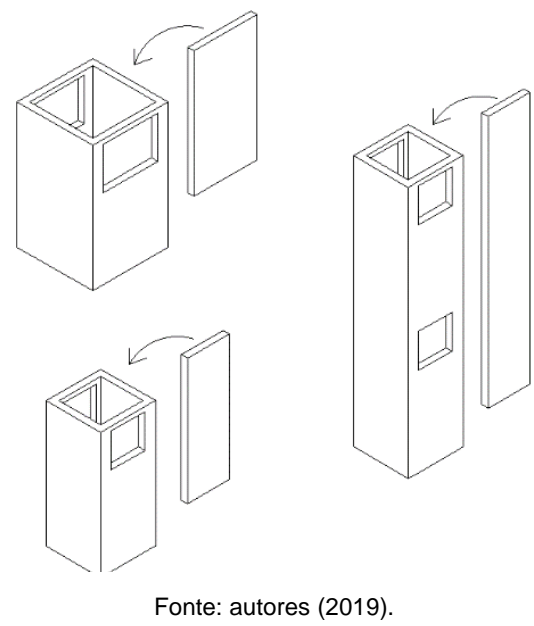

Além das duas aberturas, foi projetada a barreira central das torres para evitar a circulação cruzada do vento incidente como pode ser observado na Figura 14. Dessa forma, os três modelos permitiram realizar tanto a análise da influência de área de abertura, quanto a eficiência do sistema de torres de vento para edificações de mais de um pavimento.

Figura 14: Cortes transversais das edificações.

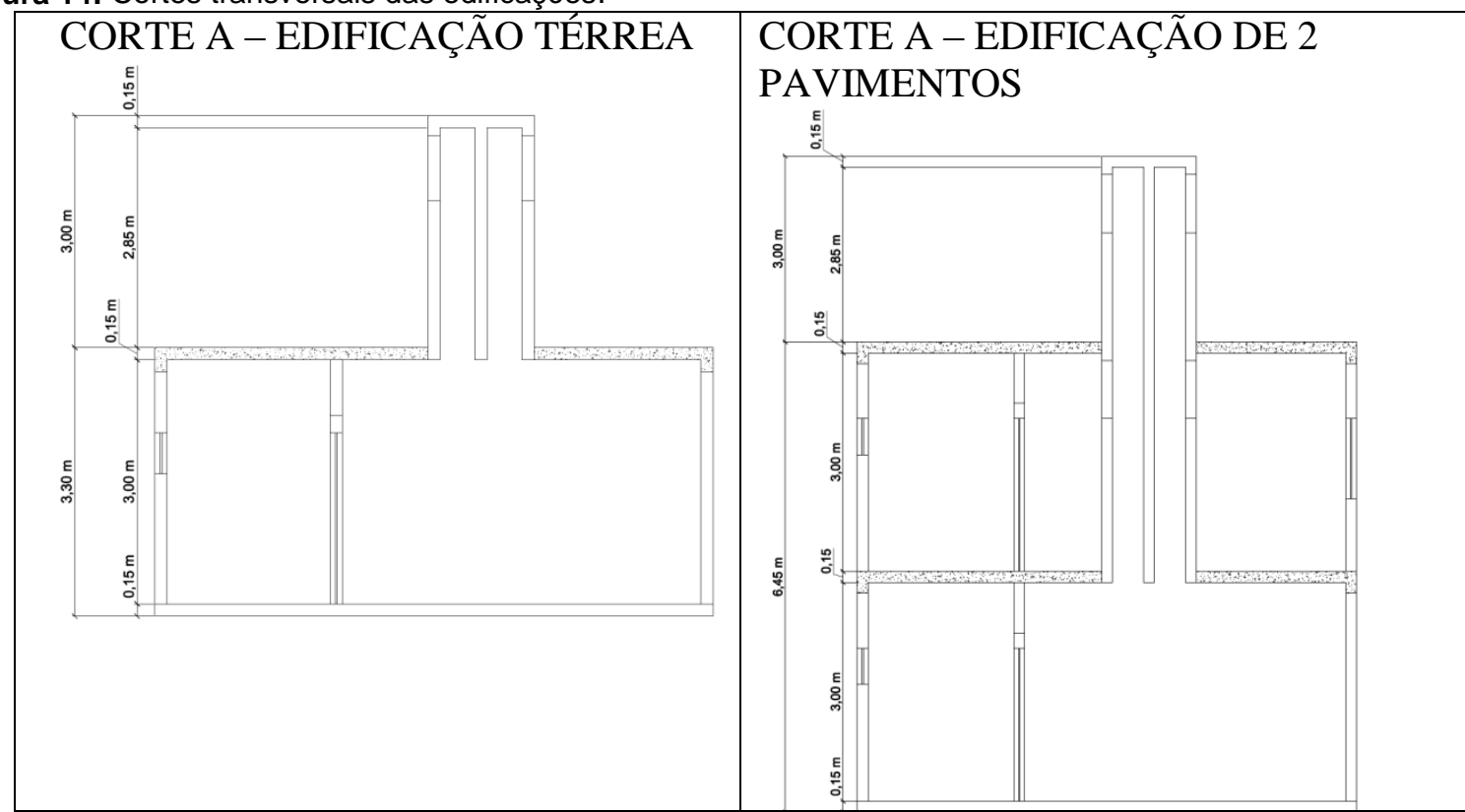

Fonte: autores (2019)

A torre da edificação de dois pavimentos (Figura 15) foi projetada de modo que, além da abertura para 
a captação da ventilação natural, houvesse duas aberturas internas à edificação, permitindo a passagem do ar captado tanto para o segundo pavimento quanto para o pavimento térreo.

Figura 15: Torre de vento da edificação de um e dois pavimentos.

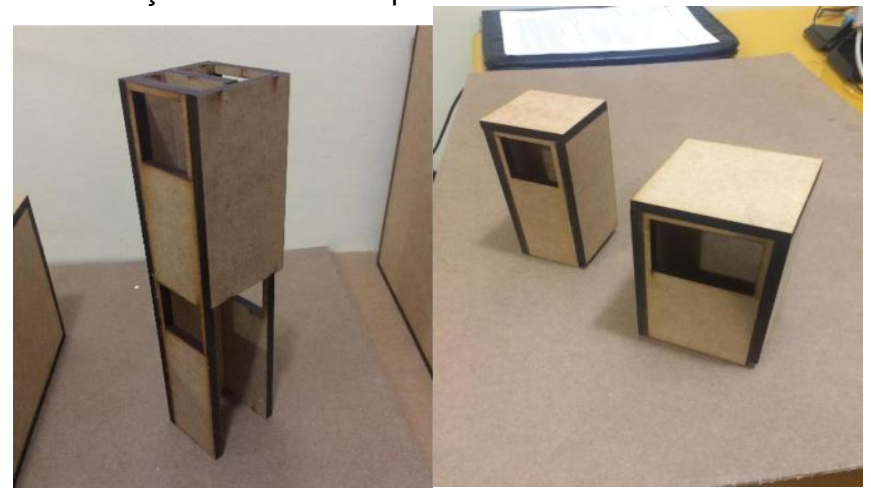

Fonte: autores (2019)

Para a edificação de um pavimento foram modeladas duas torres, com áreas de aberturas distintas, permitindo a análise da influência da geometria das aberturas na eficiência do sistema simulado.

As dimensões de todas as torres projetadas estão apresentadas na Tabela 1.

Tabela 1: Dimensões das torres de vento projetadas.

\begin{tabular}{cccc}
\hline Tipo de Edificação & $\begin{array}{c}\text { Tipo de } \\
\text { Torre }\end{array}$ & $\begin{array}{c}\text { Altura da Torre } \\
(\mathrm{m})\end{array}$ & $\begin{array}{c}\text { Área das Aberturas da } \\
\text { Torre }\left(\mathrm{m}^{2}\right)\end{array}$ \\
\hline Um Pavimento & A1 & 3 & 0,64 \\
Um Pavimento & A2 & 3 & 1,3 \\
Dois Pavimentos & B1 & 3 & 0,64 \\
\hline
\end{tabular}

Fonte: autores (2019)

\subsubsection{Construção dos modelos reduzidos}

Os modelos reduzidos das edificações foram construídos na escala 1:25 com base nas dimensões máximas exigidas pela seção de ensaio do túnel. Além disso, a escolha da escala também foi definida em função da espessura de $15 \mathrm{~cm}$ das paredes da edificação, de modo que tal dimensão correspondesse à espessura de $6 \mathrm{~mm}$ da chapa de MDF no modelo reduzido.

Inicialmente, foi feito um estudo para determinar o posicionamento inicial da torre de vento de maneira mais favorável tanto à arquitetura da edificação quanto à captação e distribuição do vento nos ambientes internos. Para tanto, foi construído com isopor, com $9 \mathrm{~mm}$ de espessura, um modelo reduzido da edificação de dois pavimentos em que foi possível deslocar facilmente a torre de vento na cobertura da edificação (Figura 16).

Figura 16: Modelo preliminar de uma casa de dois pavimentos.

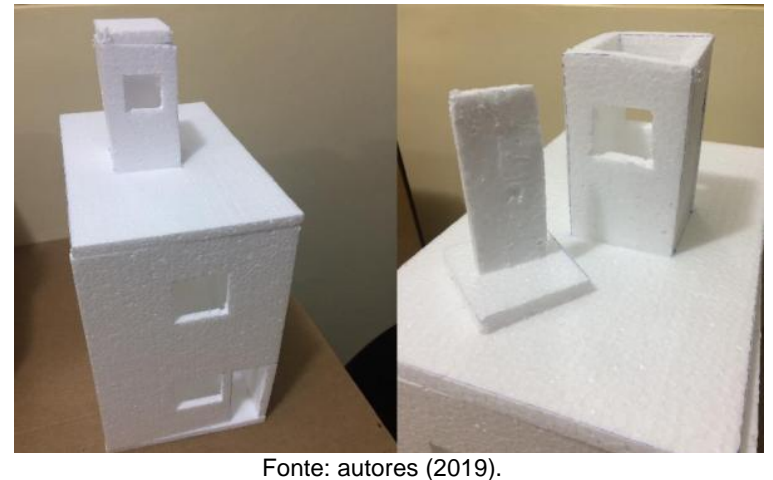


Com o auxílio de um anemômetro digital e um aparelho ventilador de uso caseiro, foi definida a posição da torre que apresentou maior variação de velocidade interna do vento comparando com a mesma edificação sem a torre de vento. Determinando assim a posição inicial do estudo detalhado a seguir.

Com o posicionamento da torre definido, foram planificadas todas as paredes das edificações no software AutoCAD (Figura 17).

Figura 17: Planificação das paredes das edificações no software AutoCAD.
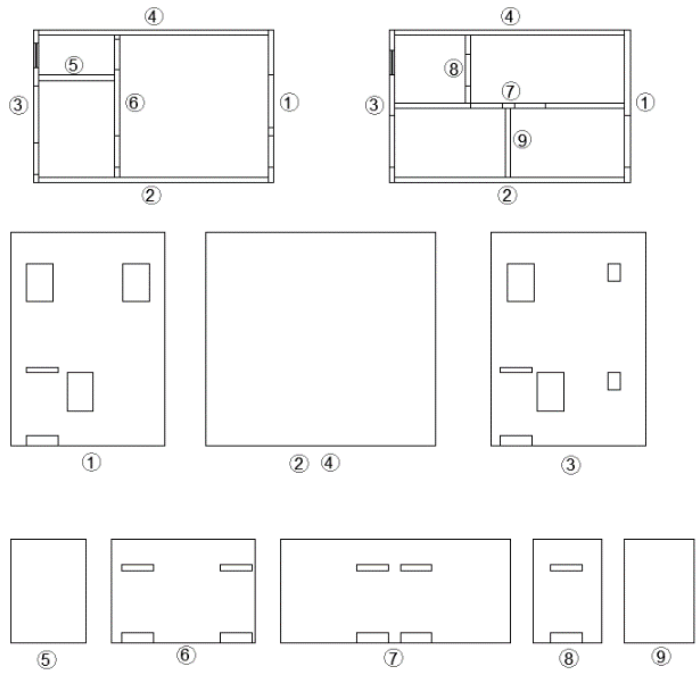

Fonte: autores (2019)

A partir das planificações, foi realizada a modelagem das edificações no software Sketchup (Figura 18), a fim de avaliar o processo de montagem e encaixe de todas as peças antes do processo de corte.

Figura 18: Modelagem das edificações no software Sketchup.

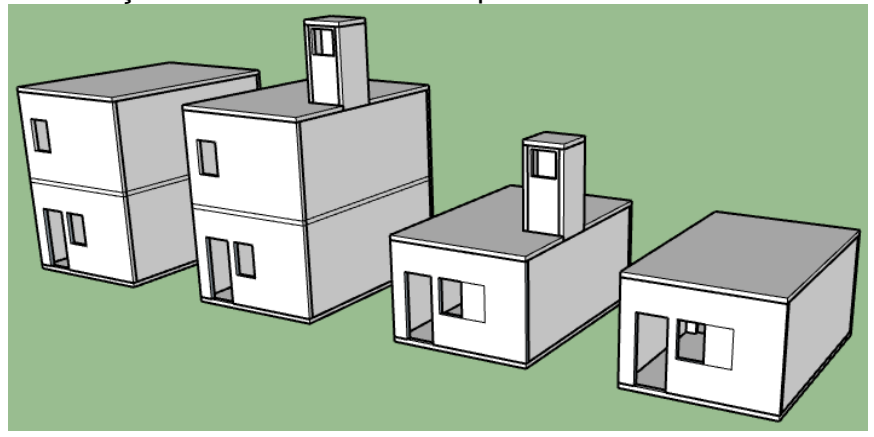

Fonte: autores (2019)

Após a finalização da modelagem eletrônica da maquete, as peças foram cortadas a laser em placas de MDF de $6 \mathrm{~mm}$ de espessura (Figura 19). Em seguida, as maquetes foram montadas com todas as divisões e detalhes necessários ao estudo (Figura 20). 
Figura 19: Corte a laser das peças em MDF.

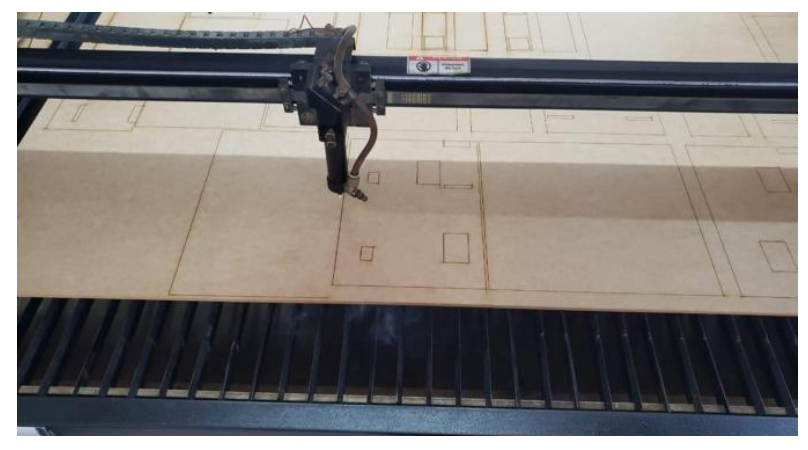

Fonte: autores (2019).

Figura 20: Modelos reduzidos utilizados nos Ensaios.
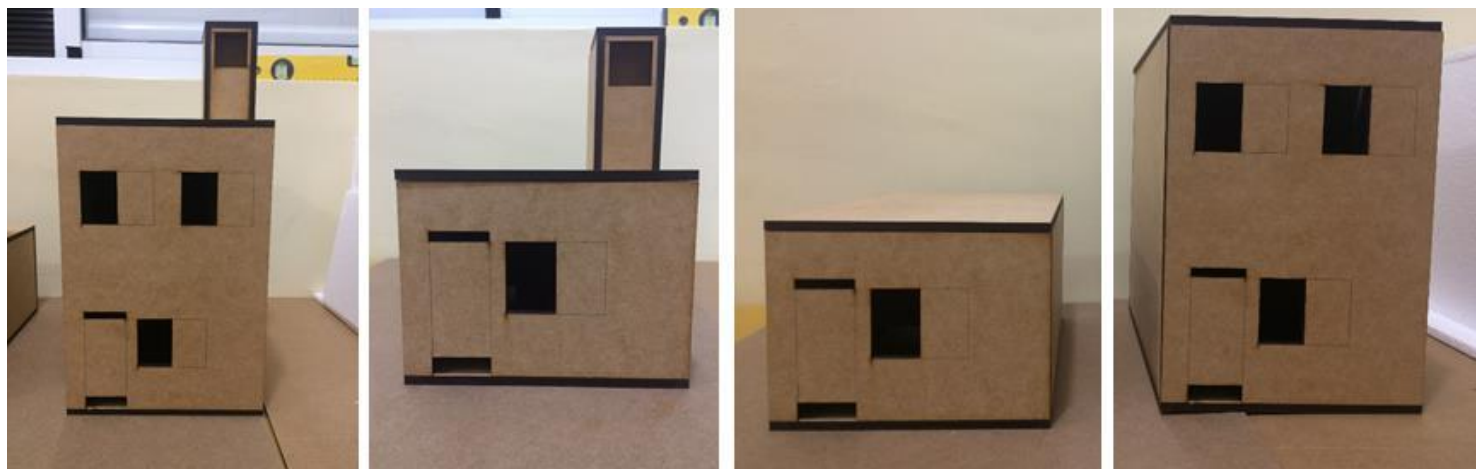

Fonte: autores (2019)

As janelas foram detalhadas considerando $50 \%$ de abertura livre para passagem de ar. Para todas as portas da edificação foram consideradas portas venezianas, com aberturas inferiores e superiores. A fim de representar apenas as frestas para entrada de ar foram instaladas malhas perfuradas (Figura 21) nas aberturas simulando a não totalidade de abertura, no total, a taxa de abertura de cada veneziana foi de aproximadamente $70 \%$.

Figura 21: Malha perfurada para simulação de venezianas.

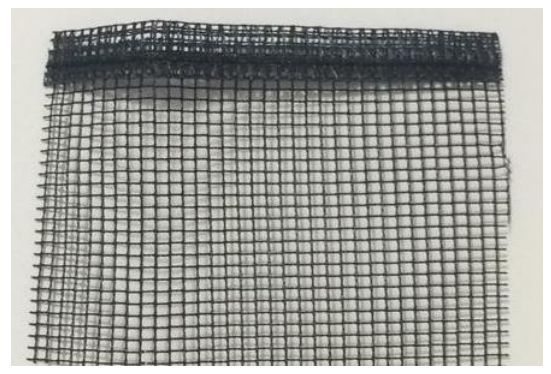

Fonte: autores (2019).

\subsubsection{Parâmetros de ensaio}

A determinação da velocidade do vento a ser desenvolvida pelo túnel de vento foi realizada por meio da análise de dados climáticos considerando o período de fevereiro de 2018 a janeiro de 2019. Os dados foram obtidos na base de dados disponibilizada pelo Instituto Nacional de Meteorologia (INMET), referente à estação automática Brasília-A001.

A fim de ser uma análise voltada para o conforto térmico do indivíduo, foi utilizado o dia típico de projeto, baseado na metodologia de Sattler (1989). Para tanto, foi calculada a média diária dos dados 
selecionados e, em seguida, foram colocados em ordem crescente. Desses valores, foi selecionado $15 \%$ do número total de dias, correspondendo ao conjunto de dias de temperaturas médias mais elevadas, denominados por dias quentes (GOULART et al., 1998).

Para os dias quentes obtidos, foi selecionado o nível de $1 \%$ para a realização do presente estudo, correspondendo ao dia 13/10/2019. As médias dos dados climáticos desse dia estão apresentadas na Tabela 2.

Tabela 2: Dados climáticos do dia 13/10/2018.

\begin{tabular}{cccccccccccccc}
\hline \multicolumn{3}{c}{ TEMPERATURA $\left({ }^{\circ} \mathrm{C}\right)$} & \multicolumn{3}{c}{ UMIDADE $(\%)$} & \multicolumn{3}{c}{ PRESSÃO $(\mathrm{hPa})$} & \multicolumn{3}{c}{ VENTO $(\mathrm{m} / \mathrm{s})$} & \multicolumn{2}{c}{ CHUVA } \\
Int. & Máx. & Mín. & Inst. & Máx. & Mín. & Inst. & Máx. & Mín. & Vel. & Dir. $\left({ }^{\circ}\right)$ & Raj. & $(\mathrm{mm})$ \\
\hline 27,01 & 27,78 & 26,33 & 34,83 & 37,13 & 32,58 & 887,03 & 887,31 & 886,80 & 1,88 & 108,79 & 4,58 & 0,00 \\
\hline
\end{tabular}

Fonte: autores (2019)

Com base na Tabela 2, a velocidade média do vento do dia típico foi igual a 1,88m/s, dessa maneira, foi definida a velocidade igual a $2 \mathrm{~m} / \mathrm{s}$ como a velocidade do vento de ensaio. Com o objetivo de simular diferentes cenários, foram definidas outras duas velocidades para o ensaio: uma representando a maior média diária de velocidade do vento no ano - aproximadamente $7 \mathrm{~m} / \mathrm{s}-$, e outra considerando uma velocidade de vento intermediaria entre os dois valores já determinados $-4 \mathrm{~m} / \mathrm{s}$.

\subsubsection{Parâmetros de programação de sensores Arduino}

Para a realização do ensaio em túnel de vento, foram empregados sensores Arduino de temperatura, possibilitando programar as entradas e saídas dos resultados de acordo com as variações captadas pelos sensores.

O sensor utilizado para a realização do ensaio foi o sensor de temperatura Ds18b20. Esse sensor apresenta precisão de até $\pm 0,5{ }^{\circ} \mathrm{C}$, sua tensão de operação é de 3 a $5,5 \mathrm{~V}$ e realiza medições de temperatura numa faixa de $-55^{\circ} \mathrm{C}$ a $+125^{\circ} \mathrm{C}$ (THOMSEN, 2015).

O sensor Ds18b20 é um sensor digital que possui um endereço serial de 64 bits possibilitando reunir vários sensores em um mesmo barramento e obtendo valores de temperatura de cada sensor separadamente (MADEIRA, 2018). A programação do sensor foi feita de modo que o mesmo retornasse valores de temperatura em graus Celsius.

A programação do sensor foi feita para os dois tipos de edificação, de modo que foram programados quatro sensores para a edificação de dois pavimentos e dois sensores para a edificação de um pavimento. As distribuições dos sensores se deu da seguinte maneira: na edificação de um pavimento, um sensor foi inserido na sala de estar e outro no quarto (Figura 22); na edificação de dois pavimentos, um sensor foi inserido na sala de estar, outros dois em cada quarto e outro na cozinha (Figura 23).

Figura 22: Distribuição dos sensores na edificação de um pavimento.

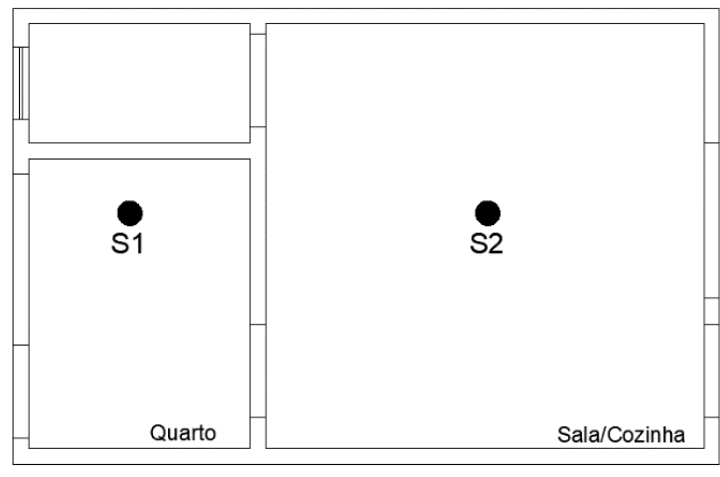

Fonte: autores (2019). 
Figura 23: Distribuição dos sensores na edificação de dois pavimentos.
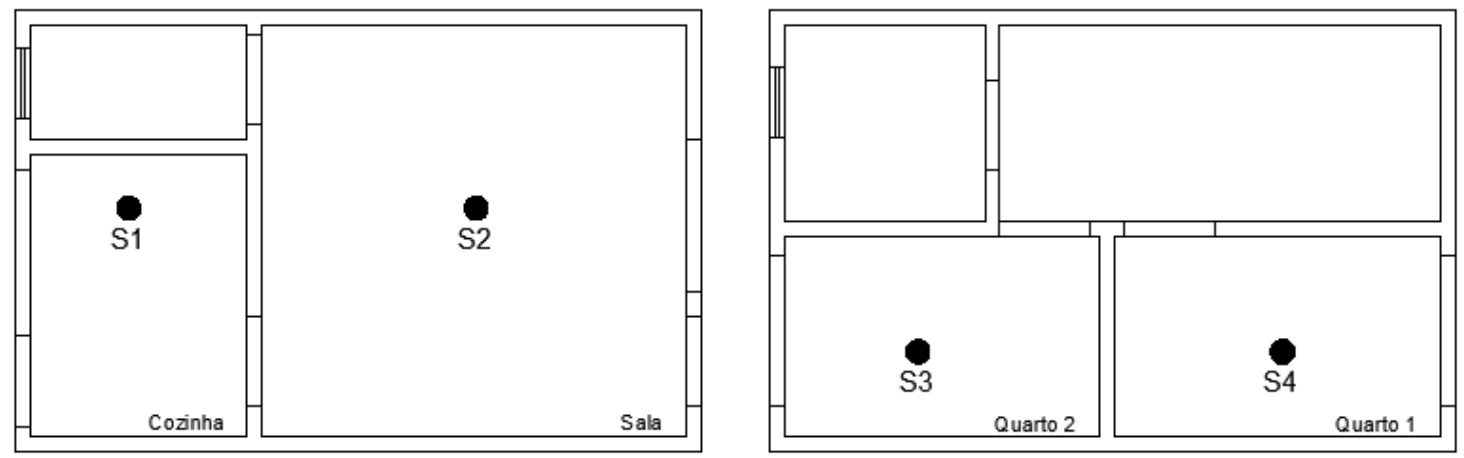

Fonte: autores (2019)

Os sensores foram instalados nas maquetes por meio de perfurações efetuadas nas bases dos modelos reduzidos, posicionados em locais afastados das portas, simulando a situação térmica mais desfavorável ao ambiente.

\subsubsection{Ensaio em Túnel de Vento}

O ensaio foi realizado no túnel de vento de circuito fechado do Laboratório de Mecânica dos Fluidos da Faculdade de Tecnologia da Universidade de Brasília (Figura 24). As dimensões da seção de ensaio do túnel de vento são de 0,6 metros de altura por 0,6 metros de largura, resultando uma área da seção transversal de ensaio de $0,36 \mathrm{~m} 2$.

Figura 24: Túnel de Vento do Laboratório de Mecânica dos Fluidos.
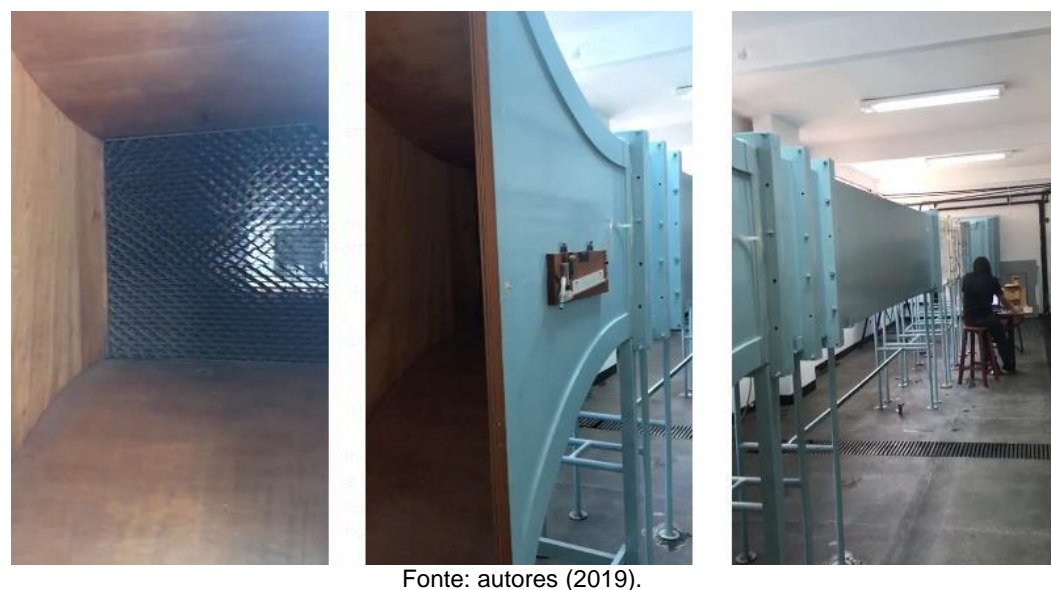

Inicialmente foi preparada área de ensaio, posicionando os sensores de temperatura dentro da seção de ensaio do túnel através de furos da sua base acrílica (Figura 25). A fim de ter maior mobilidade para os sensores, foi projetada uma base em MDF com altura de $4 \mathrm{~cm}$, em que em sua base inferior foram feitos furos coincidentes aos furos da área de ensaio e na base superior foram feitos furos localizados de acordo com os furos dos ambientes das edificações. Além dos sensores, também foi posicionado o anemômetro digital em frente ao fluxo de vento para controlar a velocidade do vento dentro do túnel. 
Figura 25: Sensores de temperatura instalados no modelo reduzido.

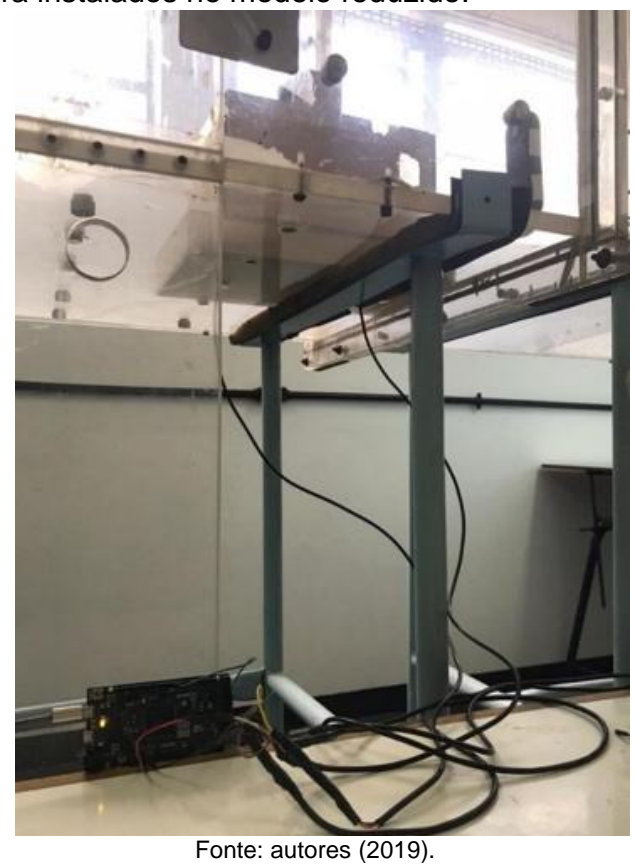

O procedimento experimental ocorreu em três etapas devido às três velocidades do vento definidas para ensaio. Dessa forma, o ensaio iniciou com o posicionamento do modelo reduzido da casa de um pavimento sem o sistema de torre de vento. Em seguida, o motor do túnel de vento foi ligado até alcançar a velocidade de $2 \mathrm{~m} / \mathrm{s}$ do fluxo de vento. Para que a temperatura fosse estabilizada, foi aguardado um período de cinco minutos para a coleta de dados. Após esse período o programa do Arduino foi iniciado e foram coletados os dados de temperatura durante um minuto.

Após a primeira coleta de dados, foi inserida a torre A1 no modelo reduzido de um pavimento e realizado o mesmo procedimento descrito anteriormente para mesma velocidade de $2 \mathrm{~m} / \mathrm{s}$. Em seguida, foi realizado o procedimento para o modelo com a torre A2. Finalizada a coleta de dados para a velocidade de $2 \mathrm{~m} / \mathrm{s}$, os ensaios foram repetidos para as velocidades de $4 \mathrm{~m} / \mathrm{s}$ e $7 \mathrm{~m} / \mathrm{s}$ do modelo de um pavimento (Figura 26).

Figura 26: Sequência do ensaio em túnel de vento - Modelo de um pavimento.
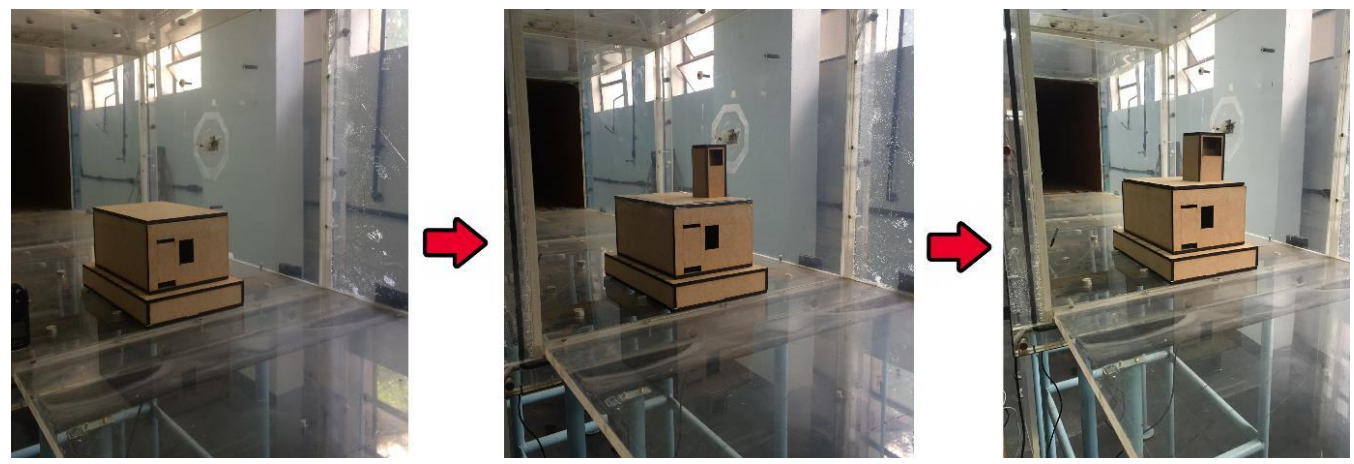

Fonte: autores (2019).

Por fim, foi realizada a instalação do modelo de dois pavimentos e, em seguida, foram realizados os mesmos procedimentos apresentados anteriormente para as três velocidades definidas (Figura 27). 
Figura 27: Sequência do ensaio em túnel de vento - Modelo de dois pavimentos.

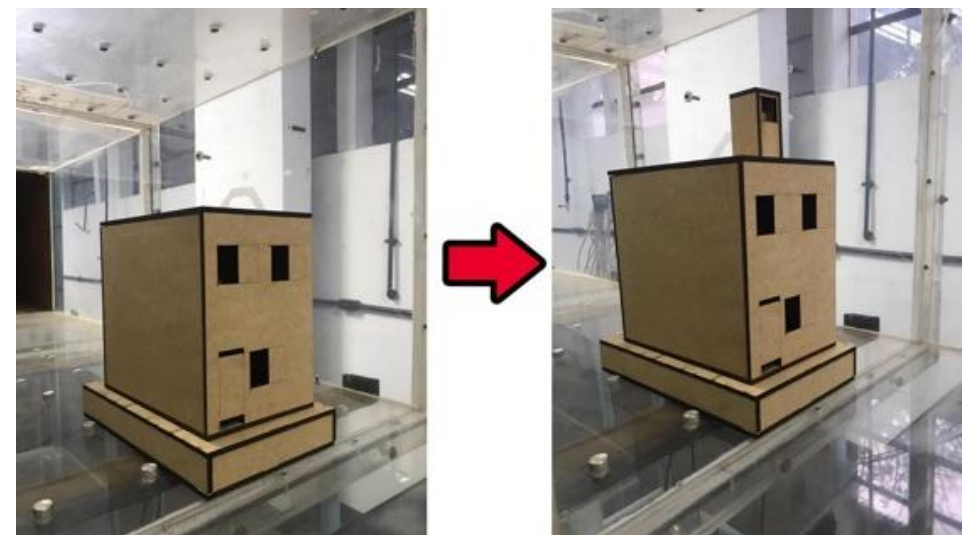

Fonte: autores (2019)

\section{Resultados e Discussão}

Com a realização dos ensaios no túnel de vento foi obtido uma grande quantidade de dados, uma vez que cada tomada de temperatura foi feita durante o período de um minuto. Dessa forma, foi realizada a média desses dados coletados para as diferentes velocidades de vento definidas.

\subsection{Modelo de um pavimento}

A Tabela 3 apresenta os resultados de temperatura obtidos para cada configuração do modelo reduzido da edificação de um pavimento, com velocidade do vento dentro do túnel igual a $2 \mathrm{~m} / \mathrm{s}, 4 \mathrm{~m} / \mathrm{s}$ e $7 \mathrm{~m} / \mathrm{s}$.

Tabela 3: Resultados de temperaturas para Casa Térrea.

\begin{tabular}{|c|c|c|c|c|c|c|}
\hline & \multicolumn{2}{|c|}{$2 \mathrm{~m} / \mathrm{s}$} & \multicolumn{2}{|c|}{$4 \mathrm{~m} / \mathrm{s}$} & \multicolumn{2}{|c|}{$7 \mathrm{~m} / \mathrm{s}$} \\
\hline $\begin{array}{l}\text { Configuração do } \\
\text { Modelo }\end{array}$ & $\begin{array}{l}\text { Senso } 1 \\
\text { (Quarto) }\end{array}$ & $\begin{array}{c}\text { Sensor } 2 \\
\text { (Sala) }\end{array}$ & $\begin{array}{l}\text { Senso } 1 \\
\text { (Quarto) }\end{array}$ & $\begin{array}{c}\text { Sensor } 2 \\
\text { (Sala) }\end{array}$ & $\begin{array}{l}\text { Senso } 1 \\
\text { (Quarto) }\end{array}$ & $\begin{array}{c}\text { Sensor } 2 \\
\text { (Sala) }\end{array}$ \\
\hline Sem torre & $27,0^{\circ} \mathrm{C}$ & $27,0^{\circ} \mathrm{C}$ & $27,0^{\circ} \mathrm{C}$ & $27,0^{\circ} \mathrm{C}$ & $27,5^{\circ} \mathrm{C}$ & $27,5^{\circ} \mathrm{C}$ \\
\hline Torre A1 & $27,0^{\circ} \mathrm{C}$ & $27,0^{\circ} \mathrm{C}$ & $27,0^{\circ} \mathrm{C}$ & $26,5^{\circ} \mathrm{C}$ & $27,0^{\circ} \mathrm{C}$ & $27,0^{\circ} \mathrm{C}$ \\
\hline Torre A2 & $26,5^{\circ} \mathrm{C}$ & $26,5^{\circ} \mathrm{C}$ & $26,5^{\circ} \mathrm{C}$ & $26,0^{\circ} \mathrm{C}$ & $26,0^{\circ} \mathrm{C}$ & $26,0^{\circ} \mathrm{C}$ \\
\hline
\end{tabular}

Fonte: autores (2019)

Observa-se que, para a velocidade de $2 \mathrm{~m} / \mathrm{s}$, não houve variação de temperatura entre o modelo sem torre de vento e o modelo com a torre $A 1$ (variação de $0 \%$ ). Já para a torre $A 2$, a variação de 
temperatura com relação ao modelo sem torre de vento foi de $0,5^{\circ} \mathrm{C}$ (variação de $1,85 \%$ ) para os dois ambientes.

Com a elevação da velocidade do vento dentro do túnel para $4 \mathrm{~m} / \mathrm{s}$, a variação de temperatura para o modelo com torre A1 ocorreu apenas no cômodo da sala, onde ocorre a saída de ar da torre de vento. Essa variação foi de $0,5^{\circ} \mathrm{C}(1,85 \%)$. Já o modelo com a torre de vento $\mathrm{A} 2$ apresentou variação de temperatura nos dois ambientes, sendo uma variação de $1^{\circ} \mathrm{C}(3,70 \%)$ na sala e de $0,5^{\circ} \mathrm{C}(1,85 \%)$ no quarto.

Para a velocidade de $7 \mathrm{~m} / \mathrm{s}$, percebe-se uma variação de temperatura comum aos dois ambientes tanto para a edificação com torre A1, quanto para a edificação com torre $\mathrm{A} 2$, sendo essa variação de $0,5^{\circ} \mathrm{C}(1,85 \%)$ e $1,5^{\circ} \mathrm{C}(5,56 \%)$ respectivamente.

De modo geral, percebe-se que a inserção da torre de vento na edificação altera a circulação do ar em seu interior, resfriando o ambiente. Para as seções de abertura das torres estudadas, temos que um aumento de aproximadamente $50 \%$ de sua área reduz a temperatura em $0,5^{\circ} \mathrm{C}(1,85 \%)$ com relação à torre com área de abertura inferior.

Além disso, temos que, para baixas velocidades de vento, as seções da torre necessitam ser próximas às seções da torre A2 para que seja possível obter variações de temperatura mais significativas. $E$, para ventos com velocidades mais elevadas, as torres com áreas de abertura maiores apresentam ainda mais eficiência quanto à redução de temperatura interna da edificação.

\subsection{Modelo de dois pavimentos}

A partir dos resultados do ensaio obtidos referentes à edificação de dois pavimentos, observou-se que, para a velocidade de vento igual a $2 \mathrm{~m} / \mathrm{s}$, a inserção da torre de vento causou variação de temperatura em todos os ambientes de maneira uniforme, variando $0,5^{\circ} \mathrm{C}(1,85 \%)$ (Tabela 4$)$.

Tabela 4: Temperaturas para velocidade do vento igual a $2 \mathrm{~m} / \mathrm{s}$ e $4 \mathrm{~m} / \mathrm{s}$ - Casa de 2 pavimentos.

\begin{tabular}{|c|c|c|c|c|c|c|c|c|}
\hline \multirow[b]{2}{*}{$\begin{array}{l}\text { Configuração do } \\
\text { Modelo }\end{array}$} & \multicolumn{4}{|c|}{$2 \mathrm{~m} / \mathrm{s}$} & \multicolumn{4}{|c|}{$4 \mathrm{~m} / \mathrm{s}$} \\
\hline & $\begin{array}{l}\text { Sensor } 1 \\
\text { (Cozinha) }\end{array}$ & $\begin{array}{c}\text { Sensor } 2 \\
\text { (Sala) }\end{array}$ & $\begin{array}{c}\text { Sensor } 3 \\
\text { (Quarto } \\
1 \text { ) }\end{array}$ & $\begin{array}{c}\text { Sensor } 4 \\
\text { (Quarto } \\
2 \text { ) }\end{array}$ & $\begin{array}{l}\text { Sensor } 1 \\
\text { (Cozinha) }\end{array}$ & $\begin{array}{c}\text { Sensor } 2 \\
\text { (Sala) }\end{array}$ & $\begin{array}{l}\text { Sensor } 3 \\
\text { (Quarto 1) }\end{array}$ & $\begin{array}{l}\text { Sensor } 4 \\
\text { (Quarto 2) }\end{array}$ \\
\hline & $26,5^{\circ} \mathrm{C}$ & $26,0^{\circ} \mathrm{C}$ & $27,0^{\circ} \mathrm{C}$ & $27,0^{\circ} \mathrm{C}$ & $26,0^{\circ} \mathrm{C}$ & $26,0^{\circ} \mathrm{C}$ & $26,5^{\circ} \mathrm{C}$ & $26,5^{\circ} \mathrm{C}$ \\
\hline Sem Torre & & & & & & & & \\
\hline & $26,0^{\circ} \mathrm{C}$ & $25,5^{\circ} \mathrm{C}$ & $26,5^{\circ} \mathrm{C}$ & $26,5^{\circ} \mathrm{C}$ & $25,5^{\circ} \mathrm{C}$ & $25,5^{\circ} \mathrm{C}$ & $26,0^{\circ} \mathrm{C}$ & $26,0^{\circ} \mathrm{C}$ \\
\hline Com & & & & & & & & \\
\hline
\end{tabular}

Fonte: autores (2019) 
Tabela 5: Temperaturas para velocidade do vento igual a $7 \mathrm{~m} / \mathrm{s}$ - Casa de 2 pavimentos.

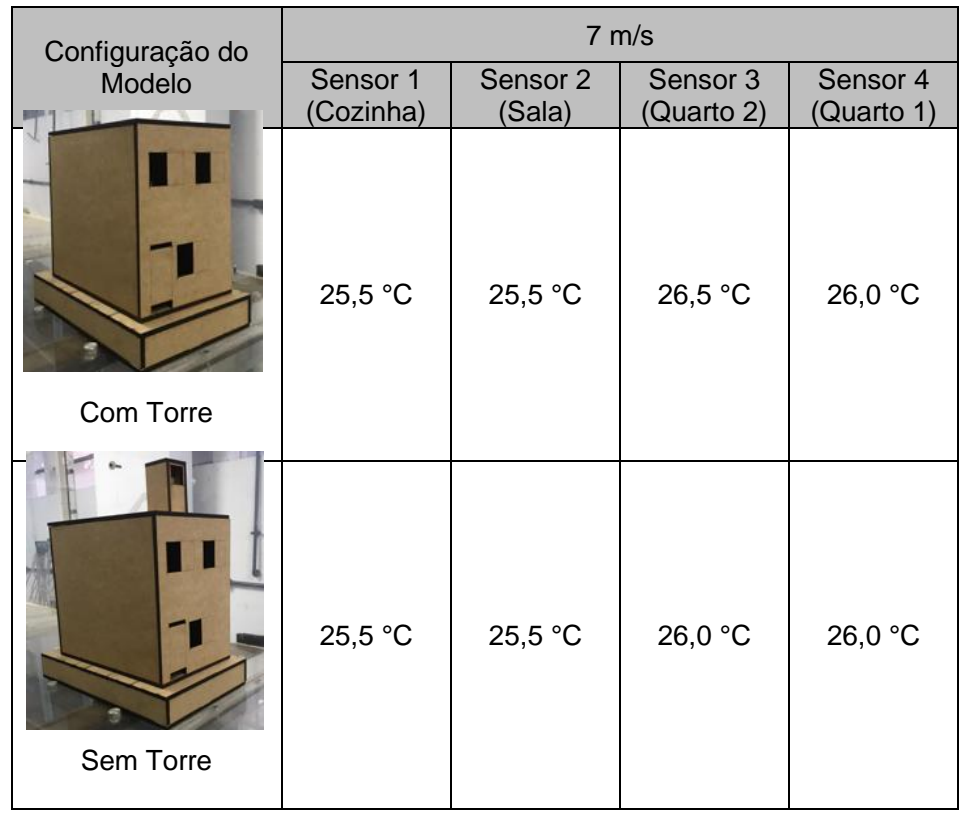

Fonte: autores (2019)

Para as velocidades do vento iguais a $4 \mathrm{~m} / \mathrm{s}$ e $7 \mathrm{~m} / \mathrm{s}$, percebe-se que foi mantido o padrão observado no ensaio com velocidade de $2 \mathrm{~m} / \mathrm{s}$, com redução de $0,5^{\circ} \mathrm{C}$ em todos os ambientes dos modelos (Tabela 4 e Tabela 5).

Para as três velocidades estudadas é possível verificar a eficiência da torre de vento na distribuição de ventilação natural para edificações de dois pavimentos, de maneira que essa distribuição reduza os índices de temperatura interna uniformemente.

\section{Conclusões}

Para quantificar o quanto é efetiva a estratégia de implementação de torres de vento em edificações residenciais Setor Habitacional Jardins Mangueiral, localizado na Região Administrativa de São Sebastião, no Distrito Federal, situado no centro-oeste do Brasil, com clima Tropical de Altitude, foram elaborados ensaios no túnel de vento com três modelos de torre em escala de 1:25. Como esperado, o modelo de torre com maior área de tomada de ar, modelo A2, ofereceu melhores resultados no qual se mediu uma redução de 1 grau no interior da edificação.

A análise dos dados de temperatura obtidos através dos ensaios em túnel de vento, apresentados no presente trabalho, demonstra que o sistema de torres de vento é eficiente tanto na redução da sensação térmica interna dos ambientes, e potencialmente pode colaborar na redução de consumo de energia elétrica reduzindo o uso dos aparelhos de ventilação mecânica nas residências.

Dentre os modelos ensaiados, a edificação de um pavimento com a torre de maior área de abertura (A2) apresentou a maior redução de temperatura interna, como seria esperado. Porém, mesmo com uma redução de $0,5^{\circ} \mathrm{C}$, os demais modelos ( $\mathrm{A} 1$ e $\mathrm{A} 3$ ) também apresentam grande capacidade de aplicação, tendo em vista que esse índice de redução pode alcançar níveis de escala de economia de energia considerando a quantidade de habitações de baixo custo que podem ser construídas com tal sistema que por princípio, não deve impactar o custo inicial da obra.

Assim, observa-se inúmeras possibilidades e vertentes que a análise de torres de vento possibilita. É preciso dar continuidade aos estudos a fim de se chegar a alternativas totalmente capazes de serem implementadas, assim como já ocorre nos hospitais da Rede Sarah Kubitschek, de modo que os projetos sejam colocados em prática, sendo respaldados pela comunidade científica e contribuindo 
para a evolução de questões ambientais e sociais.

Tratar da eficiência energética e a sustentabilidade da vida no planeta é pensar maneiras de alcançar determinados resultados minimizando o impacto em um sistema que já vem sendo sobrecarregado há séculos. O estudo realizado ao longo deste trabalho, com objetivo de pensar maneiras alternativas aos combustíveis não renováveis, possui grande importância na construção de uma sociedade mais avançada econômica, ambiental e socialmente.

Os resultados obtidos demonstram que não somente é possível, como também é necessário elaborar novas aplicações aproveitando os elementos construtivos milenares de ventilação natural. Além disso, trazer tal assunto para o campo da construção civil reforça o papel do profissional de pensar em formas alternativas de construção dos edifícios, mostrando caminhos possíveis para a construção de edifícios confortáveis aos usuários, com soluções de baixo custo e acessíveis a diferentes classes sociais.

Quanto ao presente estudo realizado, sugere-se dar continuidade levando em conta parâmetros e configurações distintos. Como propostas de continuidade pode-se destacar:

1) Avaliação comparativa das condições de temperatura interna das edificações para diferentes direções de captação de vento;

2) Estudo do fluxo de ar na entrada e saída da torre de vento;

3) Reprodução dos ensaios considerando diferentes geometrias das torres de vento;

4) Reprodução dos ensaios considerando diferentes sequências metodológicas;

5) Simulação da interferência de obstáculos externos às edificações na captação de ventilação natural;

6) Estudo do comportamento de diferentes variáveis com a implantação das torres de vento, como pressão e velocidade do fluxo de ar dentro de cada ambiente, dentre outros.

Além destas configurações e parâmetros técnicos distintos, pode-se trabalhar em avaliações do impacto de custo financeiro da implementação das torres no orçamento das residências de baixo custo.

\section{Agradecimentos}

Agradecemos à Universidade de Brasília por proporcionar a oportunidade de desenvolvimento do estudo realizado, bem como fomentar e incentivar a pesquisa científica na instituição. Agradecemos ao Prof. Dr. Lenildo Santos por todo suporte técnico oferecido durante a elaboração da pesquisa. Agradecemos ao Professor Francisco Ricardo Cunha e ao mestrando Yuri Zeniti Sinzato pelo suporte oferecido no Laboratório de Mecânica dos Fluidos.

\section{Referências}

A'ZAMI, A. Badgir in traditional Iranian architecture. International Conference "Passive and Low Energy Cooling 1021 for the Built Environment". Santorini, Greece. 2005.

AEROALCOOL. AA-TVSH50: Túnel de vento de circuito aberto. Disponível em: $<$ http://www.aeroalcool.com.br/index.php/tuneis-de-vento/25-gallery/tuneis-de- vento/30-aa-tvsh50>. Acesso em: out 2019.

ANDRADE, Nixon Cesar de. Estudo da ventilação natural em edificações com captadores de vento multidirecionais por meio de ensaios em túnel de vento e simulações computacionais. Campinas, SP, 2013. 
CASTRO, L. H. M. O uso do Arduino e do Processing no Ensino de Física, Bqqqcpr_aão de mestrado, UNIRIO / IBIO. Rio de Janeiro, 2016.

CONDIÇÕES k crcmpinígicas médicas de Brasília. Weather Spark. Disponível em: <https://pt.weatherspark.com/y/30238/Clima-caracter\%C3\%ADstico-em- Bras\%C3\%ADlia-Brasildurante-o-ano>. Acesso em: Nov 2018.

EL-SHORBAGY, A. Design with Nature: Windcatcher as a Paradigm of Natural Ventilation Device in Buildings. Architecture Department, College of Engineering. Effat University, Saudi Arabia. 2010.

EMPRESA DE PESQUISA ENERGÉTICA. EPE publica Anuário Estatístico de Energia Elétrica 2018. Disponível em: <http://epe.gov.br/pt/imprensa/noticias/epe- publica-o-anuario-estatistico-deenergia-eletrica-2018>. Acesso em: out 2018.

FROTA, A. B.; SCHIFFER, S. R. Manual de conforto térmico. 8ª Ed. Studio Nobel. 2016.248 p.

GOULART, S.; LAMBERTS, R.; FIRMINO, S. Dados climáticos para projeto e avaliação energética de edificações para 14 cidades brasileiras. 2a Edição. Florianópolis, SC. Outubro, 1998.

GIVONI, B. Passive and low energy cooling of buildings. Van Nostrand Reinhold publishing company, 1994.

HALL, N. Wind Tunnel. National Aeronautics and Space Administration. 2015. Disponível em: <https://www.grc.nasa.gov/www/k-12/airplane/shortt.html>. Acesso em: jul 2019.

JOMEHZADEH, F.; NEJAT, P.; CALAUTIT, J.K.; YUSOFa, M.B.M.; ZAKI, A.S.; HUGHES, R.B.; YAZID., N. A review on windcatcher for passive cooling and natural ventilation in buildings, Part 1: Indoor air quality and thermal comfort assessment. Renewable and Sustainable Energy Reviews, 70. pp. 736-756. ISSN 1364-0321, 2016. Disponivel em https://doi.org/10.1016/j.rser.2016.11.254, Acesso em: jan 2020.

LENGEN, J. Manual do Arquiteto Descalço.1a Ed. Ck núrio do Livro. 2009.

MADEIRA, D. DS18B20 - Sensor de temperatura inteligente. Vida de Silício, 2018. Disponível em: $<$ https://portal.vidadesilicio.com.br/sensor-de-temperatura- ds18b20/>. Acesso em: out 2019.

MCROBERTS, M. Arduino básico. Tradução Rafael Zanolli. São Paulo: Novatec, 2011. MOURA, M.; MOTTA, A. L. T. S. O fator energia na construção Civil. IX Congresso Nacional de Excelência em Gestão, 2013.

NUNES, C. A importância da ventilação natural para arquitetura bioclimática. SustentAqui, 2014. Disponível em: <https://sustentarqui.com.br/importancia-da- ventilacao-natural-para-arquiteturasustentavel/>. Acesso em: out 2018.

QUEIROZ, L. O planejamento e o futuro do setor elétrico brasileiro. GGN Energia. 2014.

Disponível em: <https://jornalggn.com.br/noticia/o-planejamento-e- o-futuro-do-setor-eletrico-brasileiro$0>$. Acesso em: out 2018.

\section{SATTLER, M. Dias Climáticos Típicos para o Projeto Térmico de Edificações em Porto Alegre.} CIENTEC, Porto Alegre. 1989.

SEDF. Jardins Mangueiral. Disponível em: < http://www.fazenda.df.gov.br/area.cfm? id_area=1318>. Acesso em: set 2019. 
SEDUH. Jardins Mangueiral. Assessoria de comunicação Sedhab. 2012. Disponível em: < http://www.seduh.df.gov.br/jardins-mangueiral-8/>. Acesso em: set 2019.

THOMSEN, A. Medindo temperatura debaixo d'água com DS18B20. Filipeflor, 2015. Disponível em: <https://www.filipeflop.com/blog/sensor-de-temperatura- ds18b20-arduino/>. Acesso em: out 2019.

TORRES de Vento. Projeteee, 2018. Disponível em:

<http://projeteee.mma.gov.br/implementacao/torres-de-vento/?cod=vn>. Acesso em: out 2018.

TCL RG?AÃO Natural. Projeteee, 2018. Disponível em:

<http://projeteee.mma.gov.br/estrategia/ventilacao-natural/>. Acesso em: out 2018. 